\title{
A literatura de autoria feminina revisitada em pesquisa minuciosa e necessária: a argúcia analítica de Eurídice Figueiredo
}

Bruno Lima ${ }^{\mathrm{i}}$

\section{RESENHA}

FIGUEIREDO, Eurídice. Por uma crítica feminista: leituras transversais de escritoras brasileiras. Porto Alegre: Zouk, 2020.

O cânone literário é motivo de reavaliações constantes. Muitos são os autores ou autoras que, por uma razão ou outra, caem no ostracismo e nem sequer figuram nas ementas dos cursos de Letras. É inegável que são as mulheres as mais prejudicadas nesse sentido, haja vista o cânone ser formado por homens e para homens. De maneira a dar visibilidade à escrita de autoria feminina, Eurídice Figueiredo escreve um livro fundamental não apenas para colocar em xeque o cânone vigente, mas, sobretudo, para lançar luz sobre uma literatura de qualidade e que merece ser lida. Seu mais recente título, Por uma crítica feminista: leituras transversais de escritoras brasileiras, é fruto de uma pesquisa de fôlego e bastante atual. Concordado com Todorov que o objetivo da literatura é a representação da existência humana e que ela nos ajuda a compreender melhor o mundo, as vozes femininas se fazem ouvir tanto na sociedade quanto literariamente, nesse último caso oferecendo aos leitores questões próprias às mulheres sob seus próprios pontos de vista. A crítica feminista, que ganhou relevância com o pósestruturalismo e os decorrentes estudos culturais, tem sido fundamental para a equidade também no que diz respeito aos textos literários, seja como forma distinta de leitura ou de escrita. Por mais que a autonomia da literatura propicie que homens criem narradoras mulheres sem que se perca a verossimilhança, somente elas são capazes de transmitir aos leitores suas idiossincrasias com uma vivência que escapa aos autores masculinos.

\footnotetext{
${ }^{\text {i }}$ Doutor em Literatura Comparada pela UERJ, com mestrado e especialização em Literatura Brasileira pela mesma universidade e graduação em Letras pela UFF.

E-mail: bruno.lima_rj@hotmail.com
} 
Eurídice Figueiredo trata do tema munida de um arcabouço teórico que respalda muito bem sua pesquisa. Não se trata de um livro panfletário, cujo discurso resvalaria no fundamentalismo comum em redes sociais. Ao contrário da discussão rasa e polarizada que em algumas ocasiões percebe-se homens contra mulheres ou vice-versa, a autora tem consciência da necessidade do feminismo ampliar a luta comum em prol da igualdade de gêneros. A quantidade de autoras analisadas e resgatadas do apagamento literário demonstra a parcialidade na formação do cânone e como nós, leitores, nos privamos de uma literatura de alto quilate que, não fosse o trabalho cada vez mais constante no meio acadêmico de resgate de mulheres escritoras desde o século XIX, permaneceríamos ignorantes e órfãos de uma estética silenciada.

A primeira parte do livro é dedicada aos problemas de gênero. Em cinco capítulos, a autora percorre teoricamente o feminismo de modo a dar sustentação à análise das obras que virão a seguir. Mais que isso, ela salienta e difere várias correntes feministas e, assim, evidencia, para além da literatura, um problema crasso da nossa sociedade: o machismo e o patriarcalismo. O conceito de mímesis, grosso modo, é responsável por levar para as páginas de ficção o que ocorre na vida social e, não raro, a literatura é considerada uma forma de se criticar, esteticamente, a sociedade. Desse modo, Eurídice Figueiredo mapeia a luta feminista também como uma maneira de se mudar o mundo, oferecendo aos leitores subsídios para a compreensão da causa por que as mulheres lutam e que deveria ser extensiva aos homens que pretendem viver em igualdade. Desde a revolução estudantil em maio de 1968 na França, que colocou em xeque a normatividade, não é mais possível vivermos sob a égide do machismo e da submissão feminina.

A segunda parte discute justamente o cânone e a margem. Além de um capítulo dedicado à história literária, cânone e crítica feminista, o qual reforça como a historiografia da literatura se pautou em textos escritos apenas por homens, a pesquisadora retrocede ao século XIX e analisa a atualidade de Júlia Lopes de Almeida, escritora muito pouco conhecida no meio literário, ao contrário de seus contemporâneos masculinos. Há um capítulo que coloca em pauta Adalgisa Nery, Pagu, Maura Lopes Cançado e Carmen da Silva, todas escritoras à margem do cânone. Pode-se afirmar que a literatura brasileira contemporânea dá mais visibilidade às escritoras, cujas obras são reconhecidas por sua qualidade, mas o que Eurídice Figueiredo revela nessa segunda 
parte é justamente a sempre presença das mulheres como autoras de peso em nossa literatura, o que apenas uma pesquisa séria e profícua seria capaz de ressaltar. O leitor de Eurídice percebe, pouco a pouco, quão ignorantes nos tornamos de nomes femininos na literatura brasileira desde sempre. A ausência quase total de escritoras nos manuais de história da literatura deve-se a quê?

Na terceira parte do livro, intitulada "Ancestralidade, filiações e trânsitos", há um capítulo dedicado à análise da escritora Maria José Silveira, exemplar da submissão e da rebeldia das mulheres na História do Brasil. Seria em vão ela ser posta à margem do cânone literário em um país patriarcal? Se lembrarmos dos destinos das personagens mulheres que ousaram transgredir o status quo, como Aurélia, em Senhora, e Lúcia, em Lucíola, ambos de José de Alencar, havemos de concordar que não era de bom tom às mulheres procurarem subverter a ordem vigente, cabendo a elas a conformidade com a sociedade regida por homens. A menção a Alencar nos remete para um país ainda escravocrata, o que dá ensejo para o segundo capítulo: "História da escravidão e da resistência dos negros: Maria Firmina dos Reis, Ana Maria Gonçalves e Eliana Alves Cruz". A obras das autoras agora discutidas resvalam em um duplo silenciamento: ser mulher e ser negra. Atualmente, o número de feminicídios no Brasil é alarmante, assim como é estatisticamente preocupante a quantidade de pessoas negras mortas diariamente. Uma mulher já necessita sobreviver ao mundo machista e misógino em que vivemos, mas quando soma-se a isso a cor da pele a dificuldade aumenta. Nesse ponto, discute-se, com argúcia, a problematização do feminismo no sentido de aliar uma bandeira à outra. O interesse da autora porém é literário, muito embora caiba a questão: são excludentes obra literária e vida civil em sociedade? Vale sublinhar que os livros de autoria feminina foram alijados do cânone não por causa de seu valor estético, mas sim devido justamente à autoria, isto é, o fato de serem escritos por mulheres. Parece evidente que o estigma literário e social caminham lado a lado, como ilustra Eurídice Figueiredo. Há ainda mais dois capítulos que encerram a terceira parte, um dedicado à narrativa de filiação, cujas autoras estudadas são Noemi Jaffe, Tatiana Salem Levy e Adriana Armony, e o último referente a trânsitos e cosmopolitismo, no qual Carola Saavedra, Julia Dantas, Carol Bensimon e Luisa Geisler servem como análise.

A quarta parte de Por uma crítica feminista: leituras transversais de escritoras brasileiras contém quatro capítulos, cada qual com uma abordagem bastante 
contemporânea, isto é, com questões muito discutidas nos dias de hoje dentre as feministas e que recebem apoio de vários segmentos da sociedade, bem como, infelizmente, críticas também de machistas convictos e retrógrados. O primeiro capítulo refere-se às relações familiares, em especial o casamento. Com argúcia, a autora discorre sobre o substancial abismo que há entre o papel que cabia às mulheres de se casarem e seguirem sua vida como dona do lar, cuja função de mãe e dos afazeres domésticos eram os únicos que lhes cabiam, para a independência propícia e pertinente nos dias de hoje. O segundo trata das autoras Amara Moira, Elvira Vigna e Maria Valéria Rezende, com o título sugestivo de "Um palimpsesto de putas". Cada uma delas aborda em suas obras a prostituição, dessa vez sob a ótica feminina, naturalmente. Eurídice Figueiredo não faz uma leitura moralista sobre o tema, mas tão-somente analisa cada um dos textos de modo a descortinar o que, literariamente, eles têm a oferecer. É importante a leitura de um tema tabu de nossa sociedade, mas sem o olhar preconceituoso e muitas vezes condenatório dos homens. A prostituição, que nada mais é do que a mercantilização sexual do corpo feminino, gera controvérsia entre as próprias feministas, umas apoiadoras, outras contrárias ao ato de se vender sexualmente. Independentemente de que lado cada um se posicione, é interessante e importante ler como mulheres abordam essa questão no âmbito literário. O terceiro capítulo trata de um lema bastante comum enfatizado pelas feministas: "meu corpo, minhas regras", no qual os direitos reprodutivos são narrados e o estupro vem à tona. $\mathrm{O}$ quarto e último capítulo dessa parte é dedicado às alegrias e agruras da velhice e traz, também, uma provocação da pesquisadora, que afirma não ser de interesse de ninguém sua vida pessoal, em função da idade, exceto para aqueles que conhecem sua trajetória acadêmica e profissional. O corpo da mulher, quando idosa, é menos visível e mais estigmatizado, como se a ela coubesse apenas a função de ajudar a criar os netos e facilitar a vida dos filhos.

A quinta e última parte, "Quebrando tabus", trata do incesto, do combate ao silenciamento do estupro, do erotismo e da lesbianidade. Todos esses temas são, naturalmente, tratados por mulheres, o que é singular porque finalmente os lemos sob a ótica feminina. Em momento algum do livro, Eurídice Figueiredo cai na armadilha de afirmar que a ótica feminina é melhor ou mais adequada, apenas dedica-se a lançar luz sobre a literatura escrita por mulheres, cuja visão e compreensão de mundo divergem da 
masculina. É exemplar o estudo de Hellen Caldwell sobre Dom Casmurro, no qual a ensaísta reclama do narrador masculino condenar Capitu sem que a mesma possua voz e oportunidade de se defender, afinal, a narrativa se constrói sob o ponto de vista de Bento Santiago. A própria teoria da recepção já alertava para a singularidade e diferença entre um texto lido por um homem e por uma mulher, por exemplo. Desse modo, Eurídice Figueiredo reavalia e problematiza o cânone e reivindica que a academia olhe com mais atenção e cuidado os textos de autoria feminina.

É inegável a subtração de autoras do circuito literário, haja vista, a título de exemplo, a primeira escritora a ingressar no panteão da Academia Brasileira de Letras, Raquel de Queiroz, só ter sido aceita em 1977. Antes, várias tentaram imortalizar-se mas não lograram permissão. Por uma crítica feminista: leituras transversais de escritoras brasileiras, de Eurídice Figueiredo, é um livro recém-lançado e importante para os estudos literários, não somente pela acuidade da pesquisa, pela excelência dos fundamentos teóricos que embasam as argumentações, pela leitura crítica e atenta de autoras esquecidas da literatura brasileira, mas sobretudo porque, ao oferecer um corpus rico, amplo e pouquíssimo estudado, complementa bastante bem a riqueza de temas e autoras de nossas letras. Diria mais: a literatura é uma forma de transformar a realidade, como pretendia Marcuse, e, nas palavras da pesquisadora, "a literatura fornece modelos combinatórios das relações humanas que podem e devem suscitar nossas reflexões de maneira a tentar mudar o mundo, estabelecendo relações mais igualitárias entre homens e mulheres." Para tanto, várias outras escritoras, além daquelas elencadas aqui, aparecem na análise de Eurídice Figueiredo como contraponto, estabelecendo o diálogo na e da literatura de autoria feminina, com o desejo de que, em um futuro próximo, como pretende a autora, abandonemos o adjunto adnominal e a denominemos simplesmente de literatura. Este é um livro fundamental para qualquer leitor que tenha interesse em ampliar seu conhecimento da literatura brasileira, irrestrita ao cânone firmado por homens e que visava ao silenciamento das mulheres no âmbito literário e, por que não, social. 